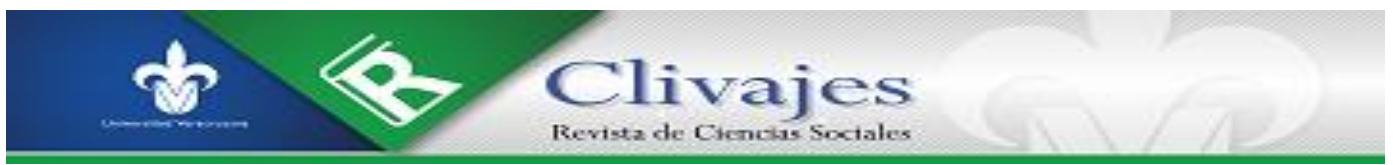

Yissel Santos González y Geidy Morfa Hernández

LA REVOLUCIÓN CULTURAL DE 1968. LA EMERGENCIA DE UNA LUCHA SOCIAL PLURAL

Clivajes. Revista de Ciencias Sociales. Año V, número 10, julio diciembre 2018, pp. 21-42.

http://clivajes.uv.mx/index.php/Clivajes/article/view/2550/4432

Instituto de Investigaciones Histórico-Sociales, Universidad Veracruzana

C livajes. Revista de Ciencias Sociales/ISSN: 2395-9495/IIH-S, UV/Xalapa, Veracruz, México.

Recibido: 09-06-2018

Aceptado: 10/07/2017

Dictaminado: $19 / 08 / 2018$

Publicación: 08/12/2018

Clivajes. Revista de Ciencias Sociales (ISSN: 2395-9495), Año V, Núm. 10, julio-diciembre, 2018 


\title{
LA ReVOLUCiÓn CULTURAL DE 1968 \\ Emergencia de una lucha social plural
}

\author{
Yissel Santos González* \\ Geidy Morfa Hernández**
}

\section{Resumen}

Las circunstancias geopolíticas actuales son las de un capitalismo en crisis, que se advierte a partir de las últimas décadas del pasado siglo XX, cuando ésta adquiere la condición de crisis civilizatoria. Se debe al debilitamiento de todas las estructuras de reproducción capitalista que hasta ese momento habían funcionado como aparatos sustentadores del sistema. El año 1968 marca la ruptura con las formas anteriores de reproducción ideológica y cultural del sistema capitalista en su dominación liberal. A partir de entonces, se produce un auge en la acción colectiva en forma de movimientos sociales que marcarían hitos en las formas de hacer política.

El alcance mundial del 68 se debe el florecimiento de varios procesos de deslegitimación de ciertas nociones acerca de la visión burguesa del mundo, como la sexualidad, la libertad, las nociones tradicionales y también muy restrictivas de la democracia, la educación, las costumbres, etc. También por el cuestionamiento de la política, al significar la crisis definitiva de la vieja izquierda tradicional. Las nuevas formas de lucha surgidas, lo hacen bajo el espíritu antisistémico de esa época. Una de las principales diferencias con los movimientos pre68 está en el carácter de las reivindicaciones. El de estas nuevas formas de acción colectiva incluye principios locales, plurales y universales, como la lucha por la paz, el medio ambiente, la justicia social, las críticas al racismo, al machismo, a la xenofobia, al pensamiento colonizador. Es la crítica y transformación de toda práctica de segregación y discriminación social.

Palabras clave:

Revolución cultural de 1968; Geocultura liberal burguesa; Movimientos antisistémicos; Luchas antidiscriminatorias

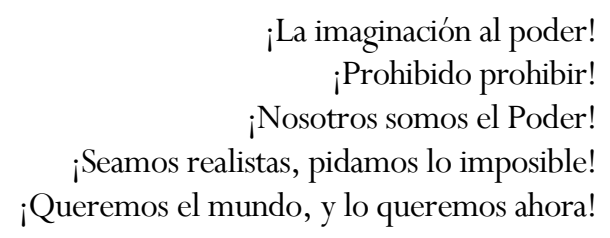

GRAFFITIS DEL MAYO FRANCÉS

\section{INTRODUCCIÓN}

El sistema-mundo capitalista se encuentra en fase de crisis terminal y ello trae consigo un reforzamiento del poder militar de la potencia dominante, a fin de mantener una hegemonía

* Estudiante de Doctorado en Ciencias Sociales y Políticas (Universidad Iberoamericana de la Ciudad de México). Becaria CONACYT.

** Estudiante de Doctorado en Ciencias Sociales y Políticas (Universidad Iberoamericana de la Ciudad de México). Ayudante de Investigación y becaria CONACYT. 
abiertamente amenazada en el plano económico y proteger la maximización contante de la ganancia. Ello viene unido al reforzamiento de una ideología ultraconservadora, nacionalista y de derecha tanto en el centro, como en los gobiernos de la periferia del sistema. Lo anterior tiene consecuencias enormes para los movimientos altermundistas que abogan por el reconocimiento y la autodeterminación de las sociedades actuales, cada vez más plurales, lo cual implica un desafío a todas las instancias de poder.

Las últimas décadas han marcado acontecimientos de gran relevancia en las luchas sociales en aras de mayores cuotas de igualdad y justicia social. La democratización real de la sociedad se ha vuelto urgente para todos, entendiéndose como necesidad de desmercantilizar a la sociedad, de cuestionar las formas dominantes del mercado y exigir los derechos esenciales como ciudadanos. A partir de la segunda mitad del siglo XX, estas formas de lucha se han propagado de distintas maneras y en escenarios muy diversos, pero específicamente a partir del año 1968. ${ }^{1}$ En esta fecha se produce una ruptura ideológica y cultural con las formas de reproducción de la dominación liberal del sistema-mundo capitalista.

La alusión a la Revolución Cultural de 1968 se sitúa referencialmente en ese año por tomar como epicentro el mayo francés; sin embargo, fue un fenómeno que recorrió un ciclo de protestas mundiales que muchos teóricos ${ }^{2}$ ubican en toda esa década, hasta comienzos de los años 70. Este es un ciclo de luchas que abarca diferentes escenarios mundiales: la Revolución Cultural China, el Mayo Francés con la imagen icónica del Che Guevara y Mao, la Primavera de Praga, la matanza de los jóvenes en la Plaza de Tlatelolco y los Juegos Olímpicos en México, las Protestas contra la Guerra de Vietnam, el Festival de Woostock, el Movimiento por los Derechos Civiles en EUA, por solo mencionar los hechos de mayor connotación, sin obviar que en muchos países del globo terráqueo se vio la emergencia de nuevos actores descontentos con la lógica de la modernidad capitalista. También este ciclo de protestas tuvo su manifestación en el plano artístico en el cine, en la literatura, la música, la pintura etc., cuestionando tanto la lógica consumista capitalista como la estética realista soviética.

El 68 significó una ruptura con las anteriores formas ideológicas de reproducción del capital e implicó el cuestionamiento directo a la ideología liberal, la ciencia social dominante,

\footnotetext{
${ }^{1}$ Durante el desarrollo del artículo se hará alusión a esta fecha también como el 68 o los acontecimientos pre68 y post68, aludiendo al año 68 del siglo XX y a las movilizaciones que se desarrollaron durante las mencionadas décadas en amplios puntos del globo terráqueo.

${ }^{2}$ En el ámbito latinoamericano, Raúl Zibechi (cit. por Bellinghausen, 2018) la sitúa entre la Revolución Cubana de 1959 y su influencia en todo el continente, hasta la caída de Salvador Allende y su muerte en el Palacio de la Moneda, en 1973, y con ello la implantación experimental del neoliberalismo bajo la dictadura militar de Augusto Pinochet. Un ciclo de luchas reivindicadoras que sacó a la palestra pública las demandas de los demás sujetos invisibilizados por la primacía del proletariado como sujeto histórico (Wallerstein, 2004).
} 
las luchas sociales y las reivindicaciones llevadas a cabo hasta el momento, desde la emergencia de otros imaginarios y la búsqueda de otros horizontes posibles. La acción social cobró a partir de entonces la forma de movimientos sociales que rompieron con la manera tradicional de lucha y cuya organización interna ya no se compone exclusivamente por clases sociales, sino por una heterogeneidad tanto clasista, étnica, sexista, nacionalista, como por el carácter de sus demandas. Interesa en este artículo analizar la importancia que tuvieron para la acción colectiva y la lucha social, en su forma de movimientos sociales, los sucesos ocurridos a nivel mundial en 1968, dado su impacto ideológico y cultural en el sistema mundial capitalista, aún hoy vigente, y que desde ese entonces se encuentra en una crisis civilizatoria. ${ }^{3}$

Esta investigación tiene como referentes teóricos a autores como Carlos Antonio Aguirre Rojas y teóricos del sistema-mundo como Immanuel Wallerstein, Samir Amin, André Gunder Frank, Giovanny Arrighi, Michael Löwy, Emir Sader, entre otros, que han analizado el impacto social, político y cultural que tuvo el 68 para el sistema-mundo capitalista y la ideología liberal burguesa.

\section{UNA RUPTURA DESDE LA OTREDAD Y LA PLURALIDAD}

El sistema-mundo capitalista ubica su génesis, hace cinco siglos, como una economía-mundo que iría incorporando todas las áreas del sistema y sus arenas exteriores. La reproducción cultural del sistema se establece en 1848, cuando la ideología liberal triunfa como ideología dominante o geocultura, a decir de Wallerstein (2005), por sobre el conservadurismo y el socialismo. El impacto social de la revolución de 1968 fue fundamental para el posterior funcionamiento de la economía-mundo capitalista. A partir de entonces comienzan a quebrantarse las formas de ¿reproducción cultural de la dominación liberal burguesa. Desde este momento, el liberalismo deja de ser asumido como la única ideología dominante, dando paso a otras que vendrían a concurrir con ella en el escenario político. Resurgen tanto la izquierda radical como la derecha conservadora, rescatando sus papeles independientes en el sistema mundial.

Autores como Jean Francois Cabral y Charles Paz (2009) consideran que 1968 no fue la última huelga del siglo XX, sino la primera huelga general donde la mayor parte de la población era asalariada. Ello demostró que nuevas formas de lucha, más allá de la clase obrera, podían ponerse en marcha y propagarse a otros sectores de la sociedad. Precisamente, una de las

\footnotetext{
${ }^{3}$ Entre el conjunto de investigadores que asumen la idea de la crisis sistémica del capitalismo a partir de esta fecha, se cuentan miembros del Consejo Latinoamericano de Ciencias Sociales (CLACSO) (Véase: Gandásegui, 2007) y teóricos del sistema-mundo, como Amin, Arrighi, Hopkins, Gunder Frank, Dos Santos y Wallerstein.
} 
trascendencias de esta revolución fue la convergencia de diversas tendencias en lucha que venían desarrollándose por separado.

El estudio sobre las protestas culturales en el año 1968 conduce al dilema planteado por muchos analistas de estos sucesos, de si fue una revolución mundial de carácter cultural o sólo fueron levantamientos espontáneos en distintas zonas del mundo, encabezados fundamentalmente por jóvenes rebeldes. Muchos de estos levantamientos han sido minimizados a lo largo de los años por la prensa y los gobiernos liberales que intentan evitar un nuevo 68. Lo cierto es que la significación social que tuvo se extendió a la mayor parte del orbe, dado el contenido de sus demandas. Su alcance se vio en las tres zonas importantes de la geopolítica mundial: Occidente (o el mundo europeo), Oriente (el llamado "bloque socialista") y en el Sur (Tercer Mundo), a pesar de que muchos paladines del orden burgués sólo hablen hoy de un fracaso y no reconozcan la verdadera repercusión de estos hechos.

Puede resultar contradictorio que en el momento de mayor auge económico del sistema capitalista y de los Estados Unidos (EUA), como potencia hegemónica mundial, ocurra un vuelco y un enfrentamiento al sistema de esta magnitud; de ataque a los pilares del sistema capitalista desde posiciones antisistémicas. Las causas de ello dependen, en cierta medida, del triunfo político, entre 1945 y 1970, de movimientos de liberación nacional en distintas zonas del mundo, y de un variado grupo de movimientos, tanto socialdemócratas como de izquierda, denominados "antisistémicos" por el carácter de sus demandas, las cuales, aunque muchas fueron absorbidas a la postre por la lógica mercantilista del sistema, lograron abrir el diapasón de luchas e hicieron más amplio, plural y complejo el enfrentamiento político. Se considera que la influencia de estos movimientos ha sido decisiva en la conformación de nuevas estrategias, más ecuménicas y democráticas de superación del sistema capitalista. Sus búsquedas, tanteos ideológicos, teóricos y prácticos fueron necesarios en el camino de construir opciones de mayor alcance teórico y capacidad superadora. Muchos de estos movimientos han ido rebasando sus posiciones iniciales sectorialistas, gremiales, por una propuesta dirigida a socavar las bases del funcionamiento del capitalismo.

La emergencia de la sociedad civil, como supuesto nuevo escenario sustitutivo de la identidad nacional, evidencia el declive definitivo del papel fundamental que ha jugado el Estado-nación, a lo largo de más de 200 años de historia, en las relaciones políticas internacionales. La situación descrita es la causa de que muchos de estos movimientos sociales se autodenominen "representantes de la sociedad civil", despojada históricamente de representatividad política. Por otro lado, esta idealización de la sociedad civil, como escenario exclusivo de lucha para la transformación social requerida, separada de la lucha política y del poder que el Estado encarna en toda transformación social, limita las posibilidades de cambio 
de estos nuevos sujetos sociales. Sin embargo, el debilitamiento relativo de los estados nacionales, sobre todo en las áreas periféricas del mundo, no debe llevar a los movimientos sociales al espejismo de obviar la lucha política.

Sucede que al mismo tiempo que buscan transformar las lógicas reproductivas del sistema, tales movimientos son resultado de éste y resulta ilusorio concebirlos fuera de la determinación política y geocultural del sistema que les dio origen. Por consiguiente, éstos se ven limitados en su estrategia por el funcionamiento político del sistema-mundo que los absorbe y, a la vez, por las ideologías simbióticas de la geocultura burguesa (universalismo y racismo-sexismo) que garantizan los mecanismos hegemónicos de la sociedad capitalista moderna (Wallerstein, 2004).

Lo anterior lleva a reafirmar la tesis marxista (1974), según la cual en tanto no se ataquen los mecanismos reales de reproducción capitalista, a saber, la propiedad privada y con ella la estructura socioclacista que la defiende, así como la división social del trabajo, polarizadora por excelencia, que caracteriza al sistema y le permite reajustarse, no se podrá alcanzar un nuevo orden social anticapitalista, con verdaderas estructuras democráticas, capaces de garantizar la equidad sociopolítica y económica que demandan estas nuevas alternativas antisistémicas.

Un análisis más profundo sobre estas nuevas alternativas, surgidas luego de la segunda mitad del siglo XX; conduce al investigador a un replanteamiento de los fundamentos mismos, a la génesis, del sistema burgués, así como del carácter antisistémico o no de estas alternativas y los sujetos que las representan. La crisis sistémica del capitalismo y la crisis geocultural que trajo consigo el fraccionamiento liberal burgués, luego del año 1968, constituyen el espacio concreto para el surgimiento de estas alternativas.

Los sucesos del 68, entendidos en este artículo como una revolución cultural mundial (Wallerstein, 2004), estuvieron dirigidos, sobre todo, a minar las bases ideológicas que garantizan la reproducción estructural del sistema capitalista y su lógica expansiva en detrimento de la vida humana. Las manifestaciones ocurridas alrededor de esta fecha, en varios lugares del sistema, se orientaron a cuestionar el poderío hegemónico de los EUA y la guerra consumada en la periferia del sistema (Vietnam). Poder que a partir de entonces comenzaría a declinar, ceñido también en la crisis del sistema-mundo que empezaba a percibirse. Al unísono atacaban, con la misma fuerza, la estrategia de los viejos movimientos, por considerarla poco coherente con su accionar real. Es la crítica a la vieja izquierda, desde el renacimiento de lo que se llamaría posteriormente "una izquierda de nuevo cuño"; crítica también a un marxismo ortodoxo y dogmático que se apartaba del marxismo clásico, llamado después "crítico", en oposición a la visión esquemática, como el estalinismo. Se condena a la propia Unión de 
Repúblicas Socialistas Soviéticas (URSS), ante la acusación de hacerle el juego a las fuerzas capitalistas y al poder de EUA, y por no cumplir con su promesa de expandir y apoyar los movimientos antisistémicos en diferentes partes del planeta, como en el Tercer Mundo, donde cobraban vigor.

A la par, significó el florecimiento de varios procesos de deslegitimación de ciertas nociones acerca de la visión burguesa del mundo, relacionadas con la sexualidad, la libertad, las nociones tradicionales y también muy restrictivas de la democracia, la educación, las costumbres, etc. También de la propia política, al significar la crisis definitiva de la vieja izquierda tradicional y con ella de los movimientos de la izquierda, cuestionándose su estrategia básica hasta entonces: la toma del poder del Estado para luego llevar a cabo paulatinamente reformas más profundas que incorporarán a los otros actores sociales no incluidos en el sujeto histórico de la revolución, el proletariado y, en casos más estrictos, el obrero industrial solamente. Para Sader (2009): "el mundo nunca más fue el mismo después de las barricadas del 68. Todos los poderes pasaron a ser cuestionados, ninguna autoridad pudo imponerse impunemente y ningún imperio pudo proclamarse imbatible" (p. 77).

El 68 desata la crisis del sistema de valores ideológicos y culturales dominante, y que arrastra consigo los principios generales impuestos en forma de paradigmas civilizatorios, a través de una hegemonía cultural, y asumidos como soporte de las cosmovisiones culturales de la modernidad hacia acá. A partir de aquí, se da una extensa crítica hacia principios como el eurocentrismo o el etnocentrismo, a la vez que comienza a renovarse las múltiples civilizaciones humanas, su diversidad, el reconocimiento de la identidad y la alteridad, el reconocimiento del otro, del dialogo transcultural; una crítica que alcanza también a las visiones machistas y patriarcales, antes dominantes, y los puntos de vista racistas y estéticos, que entraban en modelos rígidos y empobrecidos, dejando fuera la amplia gama de prácticas culturales en estas cuestiones y olvidando la multiculturalidad de los pueblos. ${ }^{4}$

En sentido general, se trata del replanteamiento de todo el sistema de saberes instituidos luego de la Revolución Francesa, con el objetivo de auxiliar el funcionamiento de la economía-mundo ante su necesidad de dominación mundial. No han hecho, por tanto, sino justificar el Estado liberal burgués y el carácter polarizador del sistema-mundo capitalista que cobró esta forma. Para Wallerstein (2004), la revolución de 1968 constituye un parteaguas en la historia moderna en tanto:

ha supuesto un triple triunfo en términos racismo, sexismo y males análogos. La primera consecuencia es que la situación legal (política estatal) ha cambiado. La segunda consecuencia es que la situación

\footnotetext{
${ }^{4}$ Para ampliar conocimientos sobre estas cuestiones, véase Aguirre-Rojas, 2005.
} 
dentro de los movimientos antisistémicos también ha cambiado. La tercera consecuencia es que la mentalidad ha cambiado. Pero no hay que ser ingenuos al respecto. Los grupos oprimidos todavía se pueden quejar, legítimamente, de que los cambios que se han producido son insuficientes de que la realidad del sexismo, el racismo y otras formas de desigualdad opresiva siguen entre nosotros. Tampoco cabe duda que hayan habido «retrocesos» en todas las áreas sobre estas cuestiones. Pero vale la pena señalar que la revolución de 1968 supuso en estas tres desigualdades un punto de inflexión histórico (p. 353).

El 68 representa a su vez, la crítica a todos los mecanismos ideoculturales del sistema capitalista, que promueve una economía de mercado, el consumo y una visión lúdica de la vida, generando, en torno a ello, desempleo, violencia, pobreza, analfabetismo, prostitución a diferentes edades, bajos salarios, una elevada seguridad social, desplazamientos, la acumulación por desposesión, y algunos más de los tantos lastres de este sistema. Lo antes apuntado son ejemplos que ilustran este cambio social que reconoce al multiculturalismo en todas sus variantes. Se está hablando del descrédito de las premisas universalistas y racistassexistas como pilares de la dominación cultural burguesa, o desde otra terminología, como la gramsciana, de contrahegemonía o hegemonía alternativa a la hegemonía, actualmente dominante, del sistema capitalista a nivel global.

Al hablar de la crisis del nivel político, no se alude sólo a la crisis de los estados ni del sistema interestatal; sino, a la vez, de los propios movimientos sociales tradicionales (tras la crisis de la vieja izquierda), una vez fracasada su estrategia política central. Pero no sólo es la crisis de la izquierda, sino del resto de las posiciones políticas, como la conservadora, la socialdemocracia, la liberal, resultado de la "crisis de la cultura política tradicional que interactúa en los marcos de la llamada democracia representativa, cuyo modelo se sustenta en la economía de mercado” (Álvarez-Somoza, 2006: 23), lo cual condujo a la crisis de los mecanismos de representatividad y, por tanto, a la búsqueda por parte de los ciudadanos, de nuevas formas de hacer política, fuera de los marcos tradicionales de la sociedad política.

Samir Amin, en conversación con Gunder Frank para Cuadernos Políticos, refiriéndose a esta crisis señala:

Se trata de una crisis estructural en el sentido auténtico del término: no de crisis coyuntural, ni de una fase recesiva normal, ni de una exigencia de simples reajustes al aumento de precios de la energía y ni siquiera de una crisis de pura demanda, de restricción de gastos en el ámbito del sistema. Se trata de una crisis que afecta al actual modelo de acumulación, su base de consenso social, el equilibrio entre el modelo de producción capitalista y las áreas periféricas, internas y externas. Una crisis, en resumen, que pone en tela de juicio modos de producción, cuadro político y sistema a alianzas sociales (GunderFrank \& Amin, 1974: 34). 
Al mismo tiempo, es una crisis de la cultura, en tanto incluye y cuestiona todas las formas de reproducción cultural de la modernidad hacia acá. En medio de estas contradicciones sociales, de la crisis tanto política y cultural del sistema capitalista, vemos una crisis de las democracias, bajo una forma inicialmente liberal y posteriormente sesgada por el neoliberalismo, como forma que adopta el capitalismo de nuestro tiempo.

El desarrollo acelerado de la economía-mundo capitalista, bajo la égida estadounidense en el período de 1945 a 1968, sostenido por la ideología liberal burguesa y unido al posterior ciclo de decadencia de esta forma concreta de reproducción, propicia el resurgimiento de lo que se llamaría posteriormente "alternativas sociales antisistémicas". Fue la época de la derrota de EUA por Vietnam, que junto al escándalo Watergate, condicionó la crisis de legitimidad de esta potencia, cuyas consecuencias arrastrarían luego en sus intentos expansivos. Tal escenario sociopolítico mundial desató lo que Michael Löwy (2009) llamó: "la expansión, a escala planetaria, de un nuevo y vasto movimiento social, con un fuerte componente anticapitalista” (p. 113). Los denominados movimientos antisistémicos que, pese a su diversidad de protestas, "asumieron, cómo uno de sus temas, los límites y los peligros del establecimiento y consolidación de estructuras burocráticas por los propios movimientos; y esto era algo nuevo" (Arrighi, Hopkins \& Wallerstein, 1999: 5).

Para autores como Wallerstein, Arrighi y Hopkins (1999), estas formas de lucha antisistémica han existido desde el siglo XIX con un carácter esencialmente político en sus inicios, aunque no siempre manifiesto. A lo largo de este siglo, es cuando surgen dos variantes primordiales de movimientos antisistémicos denominados "movimiento social" y "movimiento nacional" . El carácter realmente antisistémico de estos movimientos aún hoy es objeto de debate en los círculos académicos de las Ciencias Sociales, dado el desenvolvimiento de sus prácticas y los limitados logros históricos que han alcanzado.

Los movimientos antisistémicos post68 se diferenciarían de los movimientos pre68, los cuales se alineaban en dos grupos específicos: los socialistas, que se enfrentaron fundamentalmente a la contradicción capital-trabajo, y los nacionalistas, que emergieron sobre todo en las naciones periféricas, impugnando la división axial del trabajo entre centro y periferia (Aguirre-Rojas, 2008). Ambos movimientos trataron de alcanzar el poder del Estado, para luego transformar la lógica y las estructuras de las sociedades; sin embargo, respondían en su mayoría a una lógica verticalista, autoritaria, patriarcal, y los actores políticos revolucionarios de las naciones centrales seguían teniendo el protagonismo; incluso los

\footnotetext{
${ }^{5}$ La explicación del carácter antisistémico de estos movimientos puede encontrarse en Arrighi, Hopkins \& Wallerstein, 1999; también en Wallerstein, 2004 y 2008.
} 
movimientos nacionalistas ocurridos en la periferia tendían a imitar las formas y procedimientos de la izquierda tradicional, comandadas por las Internacionales Comunistas.

Las principales críticas a estos movimientos - llamémosle de la izquierda tradicional-, a lo largo de su trayectoria histórica, han girado en torno a su manifiesta incapacidad de suprimir las relaciones de producción capitalista que sostienen toda la superestructura política e ideológica del sistema y, por tanto, cambiar al mundo. Es común a todos estos movimientos una estrategia dirigida primeramente a la toma del poder del Estado y, solo después, como un segundo paso, una serie de acciones dirigidas a la transformación social.

En muchos casos, sólo se cumplió con el primer paso. Una vez asumido el control estatal, los movimientos chocaron con la imposibilidad o papel limitado del Estado nacional para trasformar al mundo, ya que formaban parte de un sistema político interestatal capitalista, fundamento ya advertido por el marxismo clásico, y al que en tantos trabajos Marx (1974; 1986; Marx \& Engels, s.f.) hizo referencia, destacando que el objetivo principal no debía reducirse a reformar o incluso cambiar al Estado nacional, pues ello no conducía a la ruptura del orden social vigente: el capitalismo mundial, razón por la cual condenó el nacionalismo de su tiempo, que funcionaba como mecanismo ideológico del propio sistema.

Se trataba de aprovechar la amalgama de contradicciones del sistema, sus condiciones objetivas y subjetivas para promover la revolución mundial y transformar el orden social burgués. El comunismo se presentaba como el único movimiento real superior al orden de cosas existentes. Para esta teoría clásica solo una revolución mundial, cuyo sujeto social era el proletariado internacional, podría romper las bases del sistema y por tanto ser verdaderamente antisistémica; hecho que no lograron los movimientos nacionalistas triunfantes en ningún país por poderoso que fuese.

La historia, sin embargo, siguió un curso distinto a lo previsto por la teoría clásica. Las condiciones del desarrollo capitalista cambiaron radicalmente a finales del siglo XIX, con el advenimiento del imperialismo, los procesos de democratización de la política, la consolidación de un sistema internacional de estados nacionales, fundamentalmente en Europa, que hizo necesaria una revisión a profundidad de las estrategias y tácticas de la revolución antisistémica en el nuevo escenario; cuestión que está en el fundamento mismo de la doctrina y el método de los fundadores, a saber, si las condiciones históricas cambian, se impone corregir la teoría.

A los detractores del marxismo, que se escondían tras éste, en ocasiones, para ocultar sus posturas liberales burguesas, les convino asumir este método como un esquema rígido de análisis social donde debía cumplirse invariablemente la superación social en las etapas predichas casi en forma visionaria. Asumir el marxismo de la manera descrita posibilitó el 
descrédito de su propuesta y la tergiversación de su análisis, de ahí la necesidad concreta de salvarlo, ajustándolo a las nuevas condiciones histórico-sociales.

Por lo antes apuntado sobre las consideraciones marxistas críticas sobre el método de lucha antisistémica y sus posibilidades de triunfo en el nuevo escenario histórico, es que no se debe menospreciar el rol que han jugado los movimientos de liberación nacional, y con ellos el resto de los movimientos sociales a lo largo de su historia, en el debilitamiento de las estructuras de reproducción capitalista, sobre todo a partir de 1968, aun cuando su estrategia inicial resultara limitada y se asumiera, en muchos casos, la toma del poder estatal como punto máximo y garantía de alternativas antisistémicas.

Muchos de los movimientos y de los actores sociales que hoy encarnan las luchas anticapitalistas adquirieron esta condición luego del 68. Antes fueron invisibilizados por las fuerzas tradicionales en lucha, que se reducían a la clase obrera vinculada a los medios de producción. Por eso en la teoría política contemporánea se habla de nuevas formas dentro de la lucha de clases y de hacer política. Para la construcción de estas nuevas alternativas antisistémicas fue esencial el condicionamiento de la fractura liberal. Estas formas de lucha son consideradas antisistémicas, si sus demandas van más allá de las reivindicaciones concretas por las cuales se manifiestan inicialmente, si ellos mismos se conciben dentro de una lucha global que busque quebrantar tanto el orden burgués establecido, como todo modo de dominación anterior, y no solo reformas particulares que beneficien los intereses de un determinado grupo.

Es necesario contemplar que muchos movimientos parten de reformas para luego perfilarse como antisistémicos, mientras que otros son contrahegemónicos y más tarde, mediante reformas, terminan por ser absorbidos por el sistema. Lo antisistémico, como categoría, implica también esa contradicción y es un elemento que puede aparecer intermitentemente en las diferentes etapas de resistencia contra el capitalismo global.

El surgimiento de este conjunto de actores sociales colectivos en la década de los 60 del siglo pasado terminó por producir marcas históricas en el escenario geopolítico contemporáneo. Estos nuevos actores de lucha, a decir de Jorge Orlando Blanco Suárez, "son escenarios de producción de sujetos políticos y, por tanto, de ciudadanía, son manifestaciones de la pluralidad social, política, ideológica y cultural de toda sociedad” (Blanco-Suárez, 2011: 97).

Para este autor (Blanco-Suárez, 2011), la comprensión de los movimientos sociales se hace indispensable, no sólo para pensar la democracia, sino para pensar en nuevas formas de articulación entre la sociedad política, la sociedad civil y la sociedad en general. Los movimientos sociales constituyen para él espacios de demandas y disputas sociales, donde se 
cuestiona la legitimidad de los partidos políticos, así como la noción liberal-burguesa de la sociedad civil (Blanco-Suárez, 2011). Pero esos cuestionamientos, no sólo se refieren a la idea liberal de la democracia, "fundada sobre la defensa del individualismo y las instituciones de representación como fundamento necesario y suficiente de la democracia, sino la misma idea republicana, pues por lo que luchan estos al parecer, no es por la soberanía popular, sino por la autonomía dentro de lo que Claus Offe denomina un nuevo paradigma sobre lo político” (Blanco-Suárez, 2011: 110). Este nuevo paradigma marcaría el accionar de esta forma de acción colectiva. Estos movimientos sociales no tomarían la forma tradicional pre68, como lo fue el movimiento obrero o los movimientos afiliados a una clase específica, sino que estarían caracterizados por una heterogeneidad clasista e identitaria, en tanto esta última sería un rasgo importante a la hora de distinguirlos.

La identidad colectiva que desarrollan tales nuevos movimientos es un elemento articulador en su funcionamiento; ésta les permite crear un sentido de pertenencia y compromiso de lucha que girará ya no en torno de conflictos eminentemente políticos o económicos, sino de carácter cultural y simbólico. Este nuevo rasgo dentro de la acción colectiva ha sido analizado por Alain Touraine (2006): cuando estudia los movimientos sociales, los concibe principalmente desde lo cultural, pues sus demandas son otras y diferentes a las de las sociedades preindustriales e industriales.

El conflicto social y la unidad de campo de referencias culturales se combinan para constituir los movimientos (Touraine, 2006). La lucha de estos actores va más allá de reclamar un cambio; se trata para ellos de imponer el cambio desde sus propias experiencias, desde la experimentación creativa (Players, 2015) o desde prácticas culturales que posibiliten ser ellos mismos el cambio que desean alcanzar; un enfoque compartido por Boaventura de Sousa (2001), para quien los protagonistas no son las viejas clases, pero reconoce la existencia de grupos con contornos definidos por intereses colectivos muy localizados, mas potencialmente universalizables en tanto defienden y reivindican valores universales, al tiempo que critica la concepción que intenta destacar que lo nuevo de los movimientos se centra en la afirmación de la subjetividad. El desafío de los nuevos movimientos es que en sus búsquedas puedan encontrar la síntesis entre subjetividad, ciudadanía y emancipación (De Sousa, 2001).

Para Boaventura (2004), los nuevos movimientos se plantean la democracia participativa como una política de acción social que posibilita la toma de decisiones como autogobierno. En este caso están el movimiento Zapatista en México, la lucha por la defensa de los recursos naturales y la tierra-territorio en Bolivia o el Movimiento Sin Tierra (MST) en Brasil. Se ensaya la demodiversidad, que implica el reconocimiento y la potenciación de las múltiples formas que puede asumir el ideal democrático, a lo que se le añade la articulación 
contrahegemónica entre lo local y lo global, cuestión indispensable para enfrentar el peligro del aislacionismo localista, y la ampliación del experimentalismo democrático participativo (De Sousa, 2004).

Remontarse al surgimiento de estos movimientos revela que se han organizado como grandes movilizaciones populares en contra de los efectos de las políticas económicas, por la reivindicación de identidades sociales y la inclusión social. Al constituirse como movimientos contestatarios o emancipadores, insisten en la importancia del género, la raza, la etnicidad y la sexualidad en los análisis de la realidad social, abocándose a demandas por conflictos o derechos también muy puntuales como desempleo, vivienda, infraestructura, derechos humanos, defensa de tradiciones regionales, del territorio, etc. Todas estas propuestas apuntan a un cambio geocultural.

Pueden situarse como ejemplos de estos nuevos movimientos, los movimientos ecologistas o verdes, mayormente en Europa, y los movimientos estudiantiles en EUA, México y Japón, por citar algunos; también el movimiento negro, en defensa de los afrodescendientes y contra la guerra de Vietnam en EuA, que se extendería luego a varias zonas del mundo, mientras el movimiento obrero en Europa comenzaba a revitalizarse y, también, ganaban fuerza los movimientos feminista, hippie, gay o LGBTI (lésbico, gay, bisexual, transgénero e intersexual), así como el movimiento indigenista, sobre todo en América Latina, que no constituyó un escenario ajeno a dichas contradicciones, sino que ocupó un lugar central en estas luchas, siendo la región sede hoy de uno de los más importantes focos de lucha antisistémica a través del Foro Social Mundial de Sao Paulo.

Es indispensable mencionar la labor y continuidad de distintos movimientos en América Latina, como el movimiento de los zapatistas en México, los movimientos indígenas populares en Bolivia, los indígenas en Ecuador, los piqueteros en la Argentina, los Sin Tierra en Brasil, a lo que Raúl Zibechi llamaría sociedades en movimiento (Zibechi, 2017), por ser sólo algunas muestras de la incidencia política de múltiples actores sociales en ámbitos nacionales y regionales en busca de formas creativas e innovadoras de incidir en la esfera pública y presentar sus reclamos en el seno de la sociedad, como las marchas alrededor de la pirámide de las Madres de Plaza de Mayo o las marchas por la liberación sexual en Argentina.

Lo anterior permite comprender a los movimientos sociales, en tanto formas de acción colectiva que constituyen campos de producción de discursos sobre la democracia y la ciudadanía, desmitificadas de esa concepción liberal que las restringía al voto. Como consecuencia, se da un cambio o ruptura con esos principios dominantes o pilares del sistema capitalista a través de un pensamiento crítico. Comienza a hablarse, en la práctica y en la teoría, de reivindicaciones de este tipo, invisivilizadas por las fuerzas tradicionales en lucha, 
que se reducían a la clase obrera vinculada a los medios de producción. Razón que ha conducido a que se hable, en la teoría política contemporánea, de nuevas formas dentro de la lucha social y de hacer política. Se trata, a la vez, de la defensa de los saberes y epistemologías como pensamiento alternativo, oprimido por el pensamiento colonial dominante o la colonialidad del poder (Quijano, 1992); de luchas desde la otredad, producidas desde la periferia del sistema, que reivindican formas autóctonas, sentidos de vida y tiempos otros, en ruptura con la racionalidad capitalista y el time is money.

Sus demandas recorren un amplio diapasón que pasa de reivindicaciones locales, como el derecho a la tierra de un grupo indígena en especial, hasta otras de corte universal, como la lucha contra la globalización neoliberal, la guerra, el racismo, la pobreza, el fanatismo religioso, y toda forma de discriminación y exclusión: económica, étnica, social, política, sexual o de género. Se trata de una lucha por la justicia social, por los derechos ciudadanos, la democracia participativa y el derecho de los pueblos a decidir sobre su propio futuro. A muchos de los movimientos que incluyen estas demandas abiertas y de corte global se les han denominado altermundistas, aquellos que conciben que otro mundo es posible y eminentemente necesario. Pero ese mundo deberá surgir como alternativa viable en el seno del sistema actual, en el seno de esas contradicciones. Por ello, teóricos como Sader (2001) reconocen como un desafío construir una hegemonía alternativa, anticapitalista que se apoye en las fuerzas sociales de la "sociedad civil", opuestas a otras fuerzas de la sociedad civil, buscando la transformación de las bases fundamentales de la sociedad y del Estado.

Estas propuestas de cambio tienen que transversalizar el conjunto de prácticas sociales desde la cooperación internacional por una sociedad sustentable que responda a las demandas de los pueblos, a sus necesidades alimentarias, de vivienda, salud, educación, información, agua, energía, transporte público y derechos humanos; el derecho de los pueblos a autodeterminarse, a decidir por sus territorios, sus recursos y sus formas de relación societal, ${ }^{6}$ y continuar con la crítica y erradicación de aspectos como la violencia social y patriarcal hacia la mujer, hacia las prácticas sexuales no hegemónicas y el desprecio y despojo a los campesinos, negros, indígenas. Se trata de eliminar toda práctica social discriminatoria y excluyente que los grupos de poder dominantes han enraizado por años para garantizar su dominación cultural e ideológica, garante ésta de sus intereses económicos.

Los movimientos sociales deben afrontar el reto, como los sujetos históricos de cambio social que son, de abocarse a la construcción de una nueva sociedad, despojada de los

\footnotetext{
${ }^{6}$ Se comprende lo societal desde la concepción de Luis Tapia (2008) sobre lo abigarrado de la formación nacional latinoamericana, que no obedece a la concepción tradicional de formación mononacional de los estados nacionales, sino que en un mismo espacio sociopolítico confluyen varios pueblos, naciones y etnias (p. ej., naciones afro-indígenas).
} 
prejuicios y principios capitalistas vigentes. Para ello, deberán ganar en radicalidad y compromiso de mantener el enfrentamiento social y político en las esferas de representatividad que les correspondan. Para Touraine (2006), los movimientos nunca surgen separados de reivindicaciones, de presiones, crisis ni de rupturas, que son las que permiten los diferentes tipos de lucha, entendiendo la lucha "como todas las formas de acción conflictivas organizadas y conducidas por un actor colectivo contra un adversario por el control de un campo social" (Touraine, 2006: 262). Entre dichas formas de acción, los movimientos son el tipo de lucha más importante, pero, para que ésta sea reconocida como tal, debe incluir o responder a tres condiciones principales:

En primera instancia, ésta debe ser conducida en nombre de una población particular. (...) Unos movimientos de ideas o de opiniones, un movimiento religioso o unos movimientos de tolerancia, aunque todos importantes, no pueden servir directamente de objeto para nuestra reflexión. En segundo lugar, estas luchas deben estar organizadas y no pueden existir solamente al nivel de la opinión, puesto que es necesario que exista cierta organización para que el conflicto se precise y para que el movimiento alcance cierta integración. En tercer lugar, se debe combatir un adversario que pueda estar representado por un grupo social, aun si -como a menudo sucede-, el adversario es definido en términos más abstractos: el capitalismo o el Estado. (Touraine, 2006: 262).

Desde este punto de análisis, el 68 fue un triunfo cultural e intelectual, al constituir la manera de quebrantar el conjunto de ideovalores de la cultura liberal que dominaba el mundo; por ello es que algunos autores lo restringen al escenario cultural, entre ellos Manuel Castell (2007), para quién: "La revolución de mayo de 1968 fue cultural, no política, no buscaba el poder sino disolverlo. Y ganó las mentes, no las burocracias”. Si bien su relevancia radica en el impacto cultural que tuvo, no por ello la propuesta cultural que trajo consigo pierde importancia desde el punto político. Todo lo contrario, la propuesta cultural que cobra fuerza a partir de este momento tiene una densidad política muy alta, tan solo porque sirve de soporte a una forma específica de estructuración política de la sociedad que se pretende construir. Esa nueva forma comenzará a ser objeto de debate y campo de lucha de las nuevas alternativas de construcción antisistémica en el mundo entero.

En esta perspectiva, para Alain Krivine (cit. por Verón, 2009), la importancia mayor del 68 radica en que significó un levantamiento bisagra entre el movimiento obrero tradicional y la aparición de nuevos movimientos sociales que no se limitaban a condenar la explotación, sino al mismo tiempo los mecanismos de la opresión y la exclusión capitalista. Después de estos sucesos es cuando aparecen movimientos feministas, ecologistas, antirracistas, por la libertad sexual; movimientos de indocumentados, por los derechos humanos, etc., a los que se ha denominado "reivindicaciones de los excluidos". 
Frente a estos mecanismos dominantes, se levantaron tendencias como el ecologismo, en tanto crítica a la noción del hombre como amo de la naturaleza y no como ente interdependiente de ésta. Esta lucha que ha estado representada por los llamados movimientos verdes en muchos lugares de Europa; en América Latina, mantiene continuidad con movimientos como el de los Sin Tierra en Brasil y las luchas por la preservación del Territorio Indígena y Parque Nacional Isiboro-Sécure (TIPNIS), contra el extractivismo en Tariquía, contra las consecuencias de la construcción de hidroeléctricas en Rosita y el Bala-Chepete, todas en Bolivia, que se oponen a la concepción capitalista instrumental de la tierra, comprendida ahí como Madre Tierra o Pachamama y, por tanto, propone la identidad de ésta con el hombre y su continuidad como especie, dentro de ese mundo natural que no entraña una oposición Hombre-Naturaleza.

La de Brasil y Bolivia es una protesta por la protección de la naturaleza como sujeto de derecho, por la desmercantilización de la tierra, por la eliminación de la propiedad privada; por la posición de papel terciario de nuestros países periféricos en el sistema, que funcionan como exportadores de commodities hacia el mercado mundial; en contra del extractivismo intensivo. Si la tierra es asumida como madre, no se puede poseer; en consecuencia, es una lucha por la eliminación de las clases y del capitalismo que las engendra.

El 68 fue el año en que se comenzó hablar del fracaso de los viejos movimientos en sus esfuerzos de cambiar al mundo. Su mensaje ha sido buscar formas alternativas de cambiar el orden dominante hoy. Es por eso que estos movimientos presentan como problema político descubrir una estrategia alternativa a la propuesta por la ideología liberal del siglo XIX y la primera mitad del Xx (Cisneros, 1998). Se han concentrado en rechazar las opciones inerciales que les proporciona el sistema y desean producir, para sí mismos y para otros, una identidad efectiva desde su autonomía. Por eso, la novedad de estos movimientos radica en que, plantearon "nuevas formas de hacer política" por medio de las cuales los ciudadanos encontraron cauces innovadores para construir y expresar colectivamente intereses, reivindicaciones y valores comunes.

Para Aguirre-Rojas (2010), la historia de las luchas antisistémicas muestra la edificación de "interesantes experimentos de reconstrucción social no capitalista" (p. 113), es decir, prácticas en pequeña escala de "formas económicas no regidas por la lógica de la acumulación de capital, junto a relaciones sociales solidarias y fraternas, y a proyectos de una salud, una educación, una cultura y una convivencia social, realmente alternativas a las formas burguesas capitalistas aún hoy dominantes" (pp. 113-114); o sea, luchas que incluyen prácticas geoculturales negadas por relaciones sociales de exclusión y desigualdad del moderno sistema capitalista. 
Lo anterior guarda relación con la concepción de democracia de estas nuevas alternativas, que trasciende los límites de las instituciones existentes y propone la democratización de la sociedad como un todo; que incluye la crítica a un pensamiento único ${ }^{7}$ y a la falsa idea del progreso; a la vez, es una propuesta de desmercantilización de la sociedad contemporánea, siendo éste uno de los fenómenos dentro de la economía-mundo capitalista que está agotando sus formas de reajuste.

Cuando se habla de la democratización de la sociedad, se entiende ésta de la forma descrita por Sader (2009) para el cual: "democratizar significa desmercantilizar, sacar los derechos esenciales de la ciudadanía de la esfera del mercado para transferirlos a la esfera pública, sustituir al consumidor por el ciudadano" (pp. 172-173). Sólo de esta forma el autor concibe la superación del neoliberalismo, pero debe implicar, al mismo tiempo, la refundación del Estado en torno a la esfera pública.

La importancia conferida a este proceso de desmercantilización es vital para la superación del actual sistema hegemónico. La erradicación definitiva de este fenómeno permitirá la transformación radical de las relaciones de producción capitalistas, y con ellas la totalidad de sus prácticas geoculturales burguesas. Es por ello que, para este investigador:

Cuanto más contundentes sean los elementos de desmercantilización, de socialización en los procesos de nacionalización, de construcción de formas de poder popular, de construcción de consensos de socialización, de peso del mundo del trabajo, de capacidad de lucha contra la alienación, tanto mayores serán las posibilidades de transitar del posneoliberalismo hacia el anticapitalismo y el socialismo (Sader, 2009: 182).

Para algunos, este tipo de protestas o críticas que intentan atacar dicho orden sociocultural, desde distintos espacios, constituye reclamos ajenos a las políticas de cada país o al propio sistema, pero sucede que estas diversas estructuras de reproducción cultural sirven de soporte a una forma específica de estructuración política de la sociedad capitalista; por lo tanto, el cuestionamiento hacia ellas y el reconocimiento de esta crisis geocultural permiten atacar los presupuestos ideológicos que acompañaron y sirvieron de fundamento a la burguesía liberal en la conquista del mundo, y que han evolucionado bajo distintas formas ideológicas, como actualmente el neoliberalismo.

Analizándolo desde este punto de vista, se evidencia el carácter antisistémico de los movimientos sociales, sin reducirlos a los aquí mencionados, ni incurrir en posturas

\footnotetext{
${ }^{7}$ Entendido desde la concepción de Ignacio Ramonet en enero de 1995 en un editorial de Le Monde Diplomatique, en el cual planteaba que el economicismo neoliberal se había erigido como el único pensamiento aceptable, abarcando todos los foros académicos e intelectuales (Chomski \& Ramonet, 1995).
} 
posmodernas de un optimismo carente de objetividad, pues no se debe olvidar las dificultades o limitaciones históricas que enfrentan al haber surgido dentro del propio sistema y, por tanto, limitados y marcados por éste. Es por esta razón que conviene nombrarlos movimientos que intentan hacer o llegar a alternativas antisistémicas. Este análisis exige entender la cuestión del poder o luchas sociales fuera del marxismo dogmático que, como tendencia, absolutizó el papel de la lucha por el poder del Estado, en detrimento del resto de las luchas democráticas y populares dentro del sistema, y también por su tendencia a focalizar el poder en el Estado y obviar la existencia de entidades sociales de poder (familias, géneros, razas, generaciones, etc.), concepción defendida por Foucault (1979) en su Microfísica del poder.

Podemos situar el caso del Movimiento Zapatista como uno de los de mayor experiencia en América Latina por el debate que ha suscitado acerca de su carácter sistémico o antisistémico. Lo cierto es que este movimiento, desde distintas prácticas no institucionales, intenta arrebatar espacios a la dominación capitalista y romper con las lógicas sistémicas. Esta es una característica que, si bien no puede hacerse extensiva a la totalidad de los movimientos y actores sociales latinoamericanos, si la incluyen mucho de ellos, la de mostrarse contrarios a la lógica del capitalismo (la del capital) y sus rejuegos ideológicos.

No es menos cierto que, desde su surgimiento, este movimiento superó su carácter particularista, desde demandas puramente identitarias por la defensa de los indígenas, hasta la lucha manifiesta contra el neoliberalismo y el sistema capitalista. Sucede que al cuestionarse las estrategias de lucha fallidas de los movimientos que le antecedieron, que tenían como objetivos tomar el poder estatal y guiar a partir de ahí la transformación social, se apartaron de la lucha política en el campo estatal, limitándose al plano de la sociedad civil como escenario democrático por excelencia. Se proponen entonces no tomar aparato estatal, sino construirlo desde abajo, ganarse así a la sociedad civil; de hecho, el intento de la candidata independiente del Consejo Nacional Indígena (CNI) María de Jesús Patricio Martínez (Marichuy) por llegar a la presidencia de México era un llamado a reconfigurar las redes de poder desde abajo; de llevar la lucha por la autonomía indígena a toda la sociedad mexicana, como forma de comprender el poder más allá del momento parcial del mecanismo estatal, siempre limitado y enmarcado en las conexiones capitalistas mundiales.

\section{CONCLUSIÓN}

Luego de 1848, el liberalismo ocupa el lugar dominante como ideología de la economíamundo capitalista en tanto opción centrista entre el conservadurismo y el socialismo. El 68 se enarboló como una fecha con significado de ruptura y fragmentación de la globalidad de la 
ideología liberal en el escenario político. Resurge disputando lugares en el panorama ideológico de la segunda mitad del siglo xx tanto la izquierda radical como la derecha conservadora. Con todo lo anterior, se abre un momento de fractura sociopolítica que significó un cisma social y la emergencia de amplios movimientos reivindicatorios que disputaban la legitimidad del ideal social capitalista sustentado en los principios de "libertad, igualdad y fraternidad".

El año 1968, al marcar el fraccionamiento de la geocultura liberal, marca a su vez un cambio en la cosmovisión tradicional de lo que se conocía como movimientos sociales, dando paso al florecimiento de múltiples alternativas en el pensamiento y la acción de las izquierdas mundiales, a la emergencia en esencia de un pensamiento diverso, multicultural y un peso específico en relación a la práctica y la teorización antisistémica tradicional.

Se abre un período de luchas de liberación nacional en la periferia del sistema, de crítica y deslegitimación a visiones construidas desde el ethos dominante y su visión burguesa del mundo, relacionadas con la sexualidad, la libertad, las visiones tradicionales y esquemáticas de democracia, igualdad, inclusión, educación, conjuntamente con el descrédito de la concepción sobre la modernidad capitalista desarrollada, productiva y eficiente que, a la par, significaba despojo, alienación y discriminación. La década de los 60 del siglo pasado marca el surgimiento de nuevos actores sociales como consecuencia del descrédito de las políticas estatales. Estos nuevos actores utilizan una retórica política que gira en torno a la denuncia de la opresión política, la discriminación de raza, género, religión, o sobre las distorsiones éticas de la modernidad, con la intención de transformar radicalmente la situación. No obstante, la crisis evidenció no sólo las limitaciones del sistema político y sus instituciones fundamentales, sino también las limitadas posibilidades de transformación social de estos movimientos una vez llegados al poder.

En las últimas décadas, el sistema-mundo moderno ha estado marcado por profundos procesos de transición democrática, así como por la aplicación de nuevas políticas económicas, como formas de reajuste del propio sistema, que a la vez han agudizado las contradicciones a su interior: la aplicación del modelo neoliberal constituye un ejemplo paradigmático. Esto, unido a otras condicionantes y a la emergencia en el Continente de la derecha con renovadas fuerzas, ha convertido a la sociedad contemporánea en el hervidero revolucionario que es hoy, expresión además de esta crisis geocultural.

La agudización de las contradicciones de la crisis capitalista en las últimas décadas, sobre todo al entrar en el siglo XXI, ha conducido a su vez a la ampliación de la lucha antisistémica en todo el planeta. La búsqueda de nuevas alternativas al sistema se ha convertido en foco de especial atención de disímiles organizaciones mundiales ya existentes antes de esta 
fecha, y de otras que surgieron a partir de entonces. Resemantizar los principios civilizatorios de igualdad, fraternidad y libertad se hace cada vez más necesario, si la humanidad quiere salvarse de su autodestrucción. Hoy más que nunca se debe plantear estos principios que se encuentran en crisis y proponer nuevos caminos en el logro de un orden mundial diferente, que apueste por un auténtico universalismo, alejado de la falsa idea eurocentrista de la superioridad de unas "culturas" sobre otras y parta de reconocer la pluralidad dentro de una sola cultura universal: la humana.

\section{REFERENCIAS}

Aguirre-Rojas, C. (2008). Prefacio. En Wallerstein, Historia y dilemas de los movimientos antisistémicos (pp. 5-59). México: Contrahistorias.

. (2010). Los movimientos antisistémicos de América Latina y su lucha por la tierra en el siglo XXI. Encrucijada Americana, 3(2), pp. 100-125.

. (2005). La obra de Immanuel Wallerstein y la crítica del sistema-mundo capitalista. La Habana: Centro de Investigación y Desarrollo de la Cultura Cubana "Juan Marinello".

Álvarez-Somoza, F. (2006). La izquierda en Europa: Situación actual y perspectivas. En DUARTE, E., Teoría y procesos políticos contemporáneos, vol. II. La Habana: Editorial Félix Varela.

Arrighi, G., Hopkins, T., \& Wallerstein, I. (1999). Movimientos Antisistémicos. Madrid: Editorial Akal.

Bellinghausen, H. (Junio 4 de 2018). La década más larga. La Jornada. Recuperado de http://www.jornada.unam.mx/2018/06/04/opinion/a08alcul

Blanco- SuÁrez, J. (2011). Democracia, Movimientos Sociales y Ciudadanía. Revista Republicana (10), pp. 95-125. Recuperado de http:// ojs.urepublicana.edu.co/index.php/revistarepublicana/article/view/134

CABRAL, F., \& PAZ, C. (2009). La huelga general de mayo -junio de 1968. ¿Cuál es la vigencia para los revolucionarios? En: VARIOS AuTORES, 68 francés, 40 mayos después. La Habana: Editorial Ciencias Sociales-Ruth Casa Editorial.

Castell, M. (Mayo 21 de 2007). Mayo del 68, mayo del 07. Recuperado de Firgoa. USC: http://firgoa.usc.es/drupal/node/35846

Chomski, N., \& Ramonet, I. (Enero de 1995). Cómo nos venden la moto. Información, poder y concentración de medios. Barcelona: Icaria. Recuperado de https://kmarx.files.wordpress.com/2013/11/cc3b3mo-nos-venden-la-moto-chomsky ramonet.pdf

Cisneros, A. (1998). 1968: Entrevista con Immanuel Wallerstein. Sociológica, 13(38). 
DE SousA, B. (2001). Los nuevos movimientos sociales. OSAL, pp. 177-188. Recuperado de http://www.boaventuradesousasantos.pt/media/pdfs/Los nuevos movimientos sociales osal2001.PDF . (2004). Democratizar la democracia: Los caminos de la democracia participativa. México: Fondo de Cultura Económica. Recuperado de http://181.112.151.230:8081/attachments/download/359/Democratizar\%20la\%20Democracia Los\%20caminos\%20de \%20la\%20democracia\%20participativa.pdf

Foulcault, M. (1979). Microfísica del Poder. Madrid: Ediciones de La Piqueta.

Gandásegui, M. (2007). Crisis de la Hegemonía de Estados Unidos. México: Clacso y Siglo XXI Editores. Recuperado de http://bibliotecavirtual.clacso.org.ar/clacso/coediciones/20121221125054/CrisisdeHeg

Gunder-Frank, A., \& Amin, S. (1974). Conversación sobre la crisis (pp. 32-40). México: Era (Cuadernos Políticos, 2). Recuperado de http://www.cuadernospoliticos.unam.mx/cuadernos/contenido/CP.2/CP2.4.AndreGunder.pdf

LÖWY, M. (2009). El romanticismo revolucionario de mayo del 68. En: VARIOS AuTORES, 68 francés, 40 mayos después. Editorial Ciencias Sociales \& Ruth Casa Editorial.

MarX, C. (1974). Crítica al Programa de Gotha. En: MARX, C. \& EngELS, F. Obras escogidas tomo III. Moscú: Editorial Progreso.

- (1986). El dieciocho Brumario de Luis Bonaparte. En: MARX, C. \& Engels, F. Obras escogidas en tres tomos, vol. I. Moscú: Progreso.

, \& Engels, F. (s.f.). Manifiesto del Partido Comunista. Moscú: Progreso.

PLAYERS, J. (2015). Volverse actor: dos vías para los movimientos sociales en el SXXI. Revista de Estudios Sociales, pp. 179-183. doi: https://doi.org/10.7440/res54.2015.13

Quijano, A. (1992). Colonialidad y modernidad/racionalidad. Perú Indígena, 13(29), pp. 11 20.

SADER, E. (2001). Hegemonía y contra-hegemonía para otro mundo posible. En: SEOANE, J. \& TAdDEI, E., Resistencias mundiales (De Seattle a Porto Alegre) (pp. 15-30). Buenos Aires: CLACSO. Recuperado de http://bvsde.org.ni/clacso/publicaciones/ResistenciasMundiales.pdf

. (2009). ¿Qué 68 fue aquel? En: Varios Autores, 68 francés, 40 mayos después. La Habana: Ciencias Sociales y Ruth Casa editorial.

. (2009). El nuevo topo, los caminos de la izquierda latinoamericana. Buenos Aires: Siglo XXI editores. .

TAPIA, L. (2008). Política salvaje . La Paz: Clacso, Muela del Diablo Editores y Comuna.

Touraine, A. (2006). Los Movimientos sociales. Revista Colombiana de Sociología (27), pp. 255 278. Recuperado de https://revistas.unal.edu.co/index.php/recs/article/view/7982/8626

Verón, A. (2009). Los espectros de mayo del 68. En: VARIOs AuTORES, 68 francés, 40 mayos después. La Habana: Ciencias Sociales-Ruth Casa Editorial.

Wallerstein, I. (2004). Capitalismo histórico y movimientos antisistémicos. Madrid: Akal. 
. (2005). Análisis de Sistemas-Mundo. Una introducción. Madrid: Siglo XXI Editores. . (2008) Historia y dilemas de los movimientos antisistémicos. México: Contrahistorias.

ZiBECHI, R. (2017). Movimientos sociales en América Latina. El mundo otro en movimiento. Bogotá: Desdeabajo. 